\title{
Stiffness Reduction Coefficient of Steel Plate-Reinforced Concrete Composite Coupling Beams
}

\author{
Zhangqi Hu' ${ }^{1,2,3}$, Weirong $\mathrm{Lv}^{4}$, Ran $\mathrm{He}^{1}$ and Miao Zhang ${ }^{1}$ \\ ${ }^{1}$ College of Civil Engineering, Hunan City University, Yiyang 413000, China \\ ${ }^{2}$ Key Laboratory of Key Technologies of Digital Urban-Rural Spatial Planning of Hunan Province Hunan City University, Yiyang \\ 413000, China \\ ${ }^{3} \mathrm{~A}$ dual innovation platform combining production, education and research with science and technology of the construction industry of \\ Hunan Province, Yiyang 413000, China \\ ${ }^{4}$ College of Civil Engineering, Hunan University of Science and Technology, Xiangtan 411201, China
}

Received 13 March 2021; Accepted 28 May 2021

\begin{abstract}
Steel plate-reinforced concrete composite coupling beams (SPRCs) have a wide range of applications in shear/core walls due to their several advantages, such as ease of construction and high earthquake resistance capacity. The stiffness reduction coefficient, which affects the seismic response and internal force distribution of the structure, is an important indicator among the numerous indicators of the coupling beams. However, the existing calculation methods for the stiffness reduction coefficient of coupling beams do not apply to SPRCs due to the differences in mechanical mechanisms, and no other study on the stiffness reduction coefficient of SPRCs has been reported. A simplified strut-and-tie model was created to effectively estimate the stiffness reduction coefficient of SPRCs, through model analysis, an equation that can comprehensively reflect the influencing factors of span-depth ratio, longitudinal reinforcement ratio, steel plate ratio, steel plate depth, and concrete compressive strength was proposed. The proposed equation was verified by comparison with existing experimental results. The parameter analysis and the comparison with the existing studies on the stiffness reduction coefficient of conventionally reinforced concrete coupling beams (CCBs) were carried out. Results show that the stiffness reduction coefficient of SPRC is affected by all the influencing factors, and the factors are related to each other. The interaction law between the stiffness reduction coefficient of SPRCs and the influencing factors is similar to that of CCBs. The stiffness reduction coefficient of CCBs increases with the shear member content (stirrup ratio), while that of SPRCs decreases with the increase in shear member content (steel plate), provided that the SPRC has a large spandepth ratio. This study can be used as a reference for the application of SPRCs and the seismic optimization design of shear/core walls.
\end{abstract}

Keywords: Steel plate-reinforced concrete coupling beam; stiffness reduction coefficient; strut-and-tie model; effective stiffness

\section{Introduction}

Steel plate-reinforced concrete composite coupling beams (SPRCs) have several advantages, such as high shear capacity, easy to produce, and strong energy consumption ability [1]. The SPRCs can effectively improve the seismic performance of shear/core walls, thus, an increasing number of scholars have participated in studying and designing them. The recent research [1-3] of SPRCs has concentrated on the static behavior of shear capacity and deformation performance.

However, the structure seismic process has a dynamic behavior. The stiffness reduction coefficient of coupling beams is an important parameter that affects the internal force distribution and the fundamental period [4-6], and designers would always preset it at the start of the design process. An unreasonable preset value can result in seismic calculation errors, which may affect the yielding mechanism and optimization design. Therefore, accurately predicting the stiffness reduction coefficient of coupling beams is of great importance, while the influencing factors are numerous and correlated, posing significant challenges to accurate

*E-mail address: huzhangqi0413@163.com ISSN: 1791-2377 @ 2021 School of Science, IHU. All rights reserved. doi: $10.25103 /$ iestr.142.17 estimation.

Scholars have performed a series of studies on the stiffness reduction coefficient of coupling beams [7-10]. However, the available calculation methods are mainly aimed at the conventionally reinforced concrete coupling beams (CCBs) and diagonally reinforced concrete coupling beams (DCBs). The mechanical mechanism of SPRCs is different from that of CCBs and DCBs. Hence, the existing calculation methods are ineffective for accurately predicting the stiffness reduction coefficient of SPRCs. The study on the stiffness reduction coefficient of SPRCs is yet to be published, and the influencing factor interaction mechanism of which is obscured. Therefore, determining the interaction mechanism of the different influencing parameters remains a problem.

This study constructed a reasonable simplified analysis model on the basis of the force characters of SPRC to determine the interaction mechanism between each affecting parameter of SPRC. Then, a calculation equation for the stiffness reduction coefficient of SPRCs was proposed. A parameter analysis was also conducted to study the influence of span-depth ratio, longitudinal reinforcement ratio, steel plate ratio, and concrete strength on the stiffness reduction coefficient SPRCs. This study can be used as a reference for 
the application of SPRC and the seismic optimization design of shear/core walls.

\section{State of the art}

Scholars have proposed various types of coupling beams and conducted experimental study and finite element analysis to investigate their seismic performance. Paulay et al. [11] proposed a DCB. Tegos et al. [12] proposed a rhombicreinforced concrete coupling beam. Both the reinforcement schemes were almost distributed along the principal tensile orientation, resulting in improved shear resistance and ductility of the coupling beams, but they had difficult constructions. Shahrooz et al. [13] proposed and tested a steel-reinforced composite coupling beam (SRC), the SRCs have the advantages of stable hysteresis curve and easy construction, but concrete and steel have poor cooperating performance. Subedi et al. [14] built a composite beam with steel plate embedded into the concrete. Based on Subedi' $\mathrm{s}$ study, Lam et al. [1] developed a SPRC, which was found to have several advantages, such as ease of construction, high shear resistance, and good deformability, in which concrete and the steel plate can also form a reliable bond. Tian et al. [2], Hou et al. [3], Shi et al. [15], $\mathrm{Hu}$ et al. [16], and Muhammad et al. [17] performed a series of studies to better understand the mechanical properties of SPRCs. The results showed that the steel plate can absorb most shear force, increasing the deformability of the coupling beam and forming a ductile failure mechanism. Wang et al. [18-20] applied the SPRCs to core walls and found that plastic hinges formed at the ends of the coupling beams. Accordingly, more energy was dissipated. The abovementioned studies mainly focused on the shear resistance and deformation performance of SPRCs.

Shear/core walls yield during strong and moderate earthquakes, and the stiffness of each component would accordingly degrade. The degradation degree directly affects the internal force distribution and the fundamental period. However, the correlational study has received little attention. Huang et al. [21] proposed a calculation equation for predicting the effective stiffness of shear walls, according to numerous finite element analysis (FEA) results. Sharifi et al. [22] performed statistical analysis on a numerous tests and studied the influence of the axial compression ratio, longitudinal reinforcement ratio, and depth - width ratio on the effective stiffness of shear walls. Their studies suggest that the axial compression ratio is the main influencing factor of the effective stiffness of shear walls. Although Huang and Sharifi's research focused on single shear walls, the effective stiffness of the coupling beams has a significant impact on the coupled shear/core walls. Hou et al. [23] employed SAUSAGE to analyze the damage states of the coupling beams and investigated the main influencing factors on the effective stiffness of the coupling beams. Xiao et al. [7] proposed a novel method for estimating the stiffness reduction coefficients of coupling beams, in which the stiffness reduction coefficients of coupling beams were first pre-determined. Then, the actual reduction factors and reinforcements were calculated on the basis of the inelastic analysis by using ABAQUS. However, FEA is based on a series of model assumptions, which can result in a disparity between the analysis results and the actual situation. The aforementioned studies only provide analytical methods, no quantitative analysis was involved. Chen et al. [8] investigated the indicators that influence the seismic performance of high-rise buildings, including the damping ratio and stiffness reduction coefficient of the coupling beams, on the basis of the 28 shaking table tests, meanwhile, the calculation method of the stiffness reduction coefficient of the coupling beams was not mentioned. Paulay et al. [9] and $\mathrm{Vu}$ et al. [10] proposed calculation methods for the stiffness reduction coefficients of $\mathrm{CCBs}$ and DCBs. However, the application scopes of their formulas were limited due to the insufficient understanding of the interaction mechanism of longitudinal reinforcement, concrete, stirrup, and other components. Establishing a rational simplified analysis model is an effective way for determining the structural mechanical mechanism, which helps in accurately predicting the force behavior. Kim et al. [24] proposed equations for calculating the effective stiffness of rectangular and circular concrete members based on the strut-and-tie model (STM). Bernardo et al. [25-27] proposed the GVATM, a modified variable angle truss model based on the variable angle truss model (VATM). This model can be used to effectively simulate the bending and torsion behavior of the precast concrete beams. Dhahir et al. [28] analyzed the shear behavior of fiber-reinforced polymer strengthened beams (FRPSBs) by using the STM and proposed a calculation formula for the shear capacity of FRPSBs. Nabilah et al. [29] proposed a nonlinear strut-andtie model (NSTM). The test results showed that NSTM can be used to effectively estimate the force behavior and failure mode of beams. Luís et al. [30] proposed a generalized softened variable angle truss-model (GSVTAM), which can accurately predict the torsion behavior of concrete beams. Many scholars, including Xia et al. [31, 32], Melendez et al. [33], Yun et al. [34], and Zhou et al. [35], used STM to conduct force analysis on the structures, and good results were achieved. This research team [36] proposed a calculation equation for the stiffness reduction coefficient of CCBs based on the STM in 2020, which was proven to be more reliable and practical than the theoretical formulas proposed by Paulay et al. [9] and Vu et al. [10]. However, the available calculation methods are limited to CCBs and DCBs. The force mechanism of SPRCs is different from those of CCBs and DCBs, hence, they cannot be used to accurately predict the stiffness reduction coefficient of the SPRCs. The stiffness reduction coefficient of SPRCs has not yet been investigated. The STM has the advantages of determining the force transfer mechanism and simple calculation, thus, it can be used in the force analysis of the effective stiffness of the coupling beams, which is helpful in clarifying the interaction mechanism of various influencing factors and improving the prediction accuracy and application scope.

This study proposes an equation for calculating the stiffness reduction coefficient of SPRCs and investigates the influence of the span-depth ratio, longitudinal reinforcement ratio, steel plate ratio, and concrete strength through parameter analysis. The study results can be used as a reference for the design and optimization of the shear/core walls.

The remainder of this study is organized as follows. Section 3 presents the definition and existing calculation equations of the stiffness reduction coefficient of the coupling beams and establishes a simplified analysis model. Section 4 proposes the theoretical equation and verifies its reliability and superiority by comparison with existing test data and calculation methods. Furthermore, relevant parameters are analyzed. Finally, Section 5 summarizes this study and draws conclusions. 


\section{Methodology}

3.1 Definition of stiffness reduction coefficient of coupling beam

The stiffness reduction coefficient of coupling beam is defined as follows:

$\kappa=\frac{K_{\mathrm{e}}}{K_{\mathrm{g}}} \frac{K_{\mathrm{e}}}{E_{\mathrm{c}} I_{\mathrm{g}}} \bullet \frac{l^{3}}{12}=\frac{I_{\mathrm{e}}}{I_{\mathrm{g}}}$

where $K_{\mathrm{e}}$ denotes the effective stiffness of the coupling beam, $K_{\mathrm{g}}$ represents the initial stiffness of the coupling beam, $l$ is the beam span, $E_{\mathrm{c}}$ is the elastic modulus of concrete, $I_{\mathrm{e}}$ denotes the effective moment of inertia of the coupling beam, and $I_{\mathrm{g}}$ is the initial moment of inertia of the coupling beam.

The effective stiffness $[37,38]$ can be generally defined as the secant stiffness of the structure at $75 \%$ ultimate strength, as shown in Fig. 1 and Eq. (2):

$$
K_{\mathrm{e}}=\frac{V_{\mathrm{y}}}{\Delta_{\mathrm{y}}}
$$

where $V_{\mathrm{y}}$ is the yield lateral force, and $\Delta_{\mathrm{y}}$ is the yield displacement.

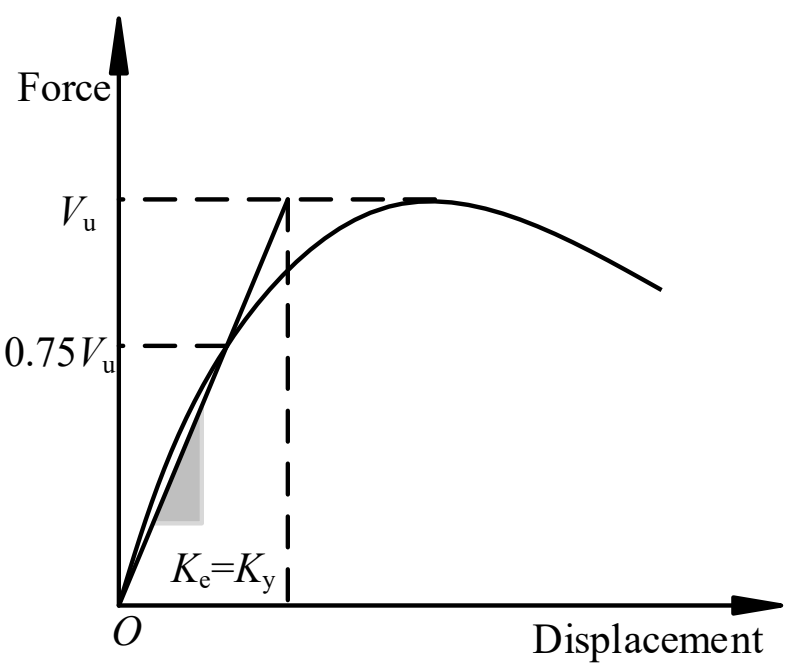

Fig. 1. Definition of effective stiffness

\subsection{Available calculation methods}

(1) Paulay [9]

Paulay et al. [9] proposed Eqs. (3) and (4) to calculate the stiffness reduction coefficient of $\mathrm{CCBs}$ and $\mathrm{DCBs}$, respectively:

$$
\begin{aligned}
& \kappa=\frac{I_{\mathrm{e}}}{I_{g}}=0.67\left(1.8 \frac{l}{d}+0.4 \frac{l^{2}}{d^{2}}\right)\left(0.9+0.7 \rho_{\mathrm{v}}+1.1 \rho_{\mathrm{s}}\right)\left(0.5+\frac{11}{f_{\mathrm{c}}{ }^{\prime}}\right) \\
& \kappa=\frac{I_{\mathrm{e}}}{I_{\mathrm{g}}}=0.65\left(1.6+0.9 \frac{l}{d}\right)\left(0.4+1.7 \rho_{\mathrm{sd}}\right)\left(0.7+\frac{14}{f_{\mathrm{c}}{ }^{\prime}}\right)
\end{aligned}
$$

$$
\begin{aligned}
& I_{\mathrm{e}}=\frac{0.2 I_{\mathrm{g}}}{1+3(d / l)^{2}} \\
& I_{\mathrm{e}}=\frac{0.4 I_{\mathrm{g}}}{1+3(d / l)^{2}}
\end{aligned}
$$

where $d$ is the effective depth.

(2) NZS 3101 [4]

NZS 3101 [4] suggests an equation for estimating the stiffness reduction coefficient of CCBs, as shown in Eq. (5), and Eq. (6) is for the DCBs:

$I_{\mathrm{e}}=\frac{0.4 I_{\mathrm{g}}}{1+8(d / l)^{2}}$

$I_{\mathrm{e}}=\frac{A I_{\mathrm{g}}}{B+C(d / l)^{2}}$

where $A=1.0, B=1.7$, and $C=1.3$ when $\mu=1.25$ and $A=0.4$, $B=1.7$, and $C=2.7$ when $\mu=6.0$.

\section{(3) $\mathrm{ACI} 318-14$ [5]}

ACI318-14 [5] provides two methods to calculate the effective stiffness of the coupling beams: a value of $0.35 E_{\mathrm{c}} I_{g}$, or calculated with Eq. (7).

$$
I_{\mathrm{e}}=\left(0.1+25 \rho_{\mathrm{s}}\right)\left(1.2-\frac{0.2 b}{d}\right) I_{\mathrm{g}}
$$

where $\rho_{\mathrm{s}}$ is the longitudinal reinforcement ratio, $b$ represents the width of the coupling beam, and $0.25 I_{\mathrm{g}} \leq I_{\mathrm{e}} \leq 0.5 I_{\mathrm{g}}$.

\section{(4) $\mathrm{Hu}[36]$}

$\mathrm{Hu}$ et al. [36] proposed an equation for predicting the stiffness reduction coefficients of CCBs, as shown in Eq. (8):

$$
\kappa=\frac{4.44 n \rho_{\mathrm{sv}} \rho_{\mathrm{s}} l^{4} / h^{4}}{1.52 \rho_{\mathrm{sv}} l^{4} / h^{4}+n \rho_{\mathrm{sv}} \rho_{\mathrm{s}}\left(1.23 l^{2} / h^{2}+4\right)^{2}+32 \rho_{\mathrm{s}}}
$$

where $l / h$ is the span-depth ratio of the coupling beam, $n$ denotes the ratio of elastic modulus of the steel bar to concrete, and $f_{\mathrm{cu}}$ represents the compressive strength of the concrete cube.

(5) $\mathrm{Vu}[10]$

$\mathrm{Vu}$ et al. [10] proposed two equations for estimating the stiffness reduction coefficients of CCBs and DCBs, as shown in Eqs. (9) and (10), respectively. 
where $f_{\mathrm{c}}^{\prime}$ is the compressive strength of the concrete cylinder, $\rho_{\mathrm{sv}}$ is the stirrup ratio of the coupling beam, and $\rho_{\text {sd }}$ is the diagonal reinforcement ratio.

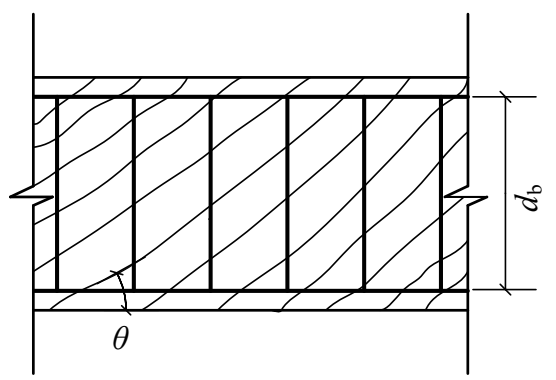

(a)

Fig. 2. Constant angle truss model (CATM)

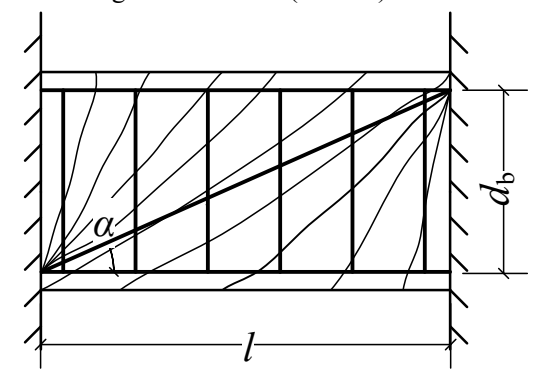

(a)

Fig. 3. Variable angle truss model (VATM)

The author of this article [36] simplified CATM and VATM. A simplified model for analyzing the stiffness reduction coefficient of $\mathrm{CCB}$ was proposed in combination with the inverse bending point method [39], and good results were achieved. The simplified model is shown in Fig. 4

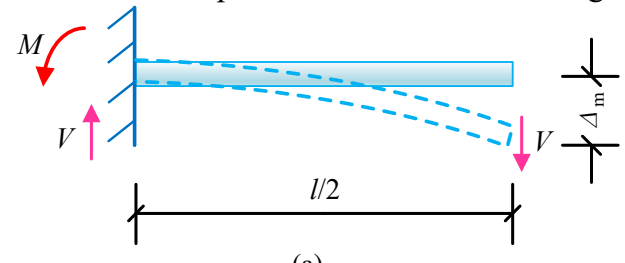

(a)

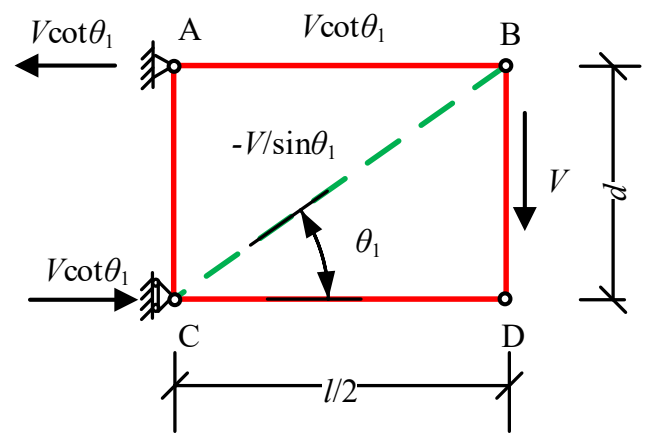

(b)

Fig. 4. Simplified analysis model of CCB. (a)Cantilever beam. (b)Force of each component of the coupling beam

The reverse bending point of SPRC is assumed to be located in the middle of the coupling beam, according to the method provided by reference [36]. Accordingly, the coupling beam can be converted to a cantilever beam, as shown in Fig. 4(a). The compressive stress is transferred to the support in the shortest path, and the deformation at the end of the coupling beam $\left(\Delta_{\text {end }}\right)$ is equal to $2 \Delta_{\mathrm{m}}\left(\Delta_{\mathrm{m}}\right.$ is the deformation in the middle portion of the coupling beam).

\subsection{Establishment of the simplified analysis model}

Based on the constant angle truss model (CATM, shown in Fig. 2) and VATM (Fig. 3), Vu et al. [10] created two equations for estimating the stiffness reduction coefficients of CCBs and DCBs.

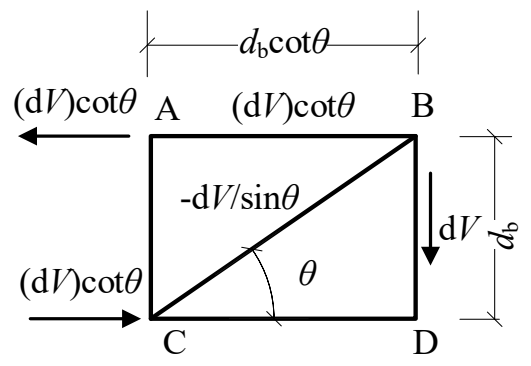

(b)

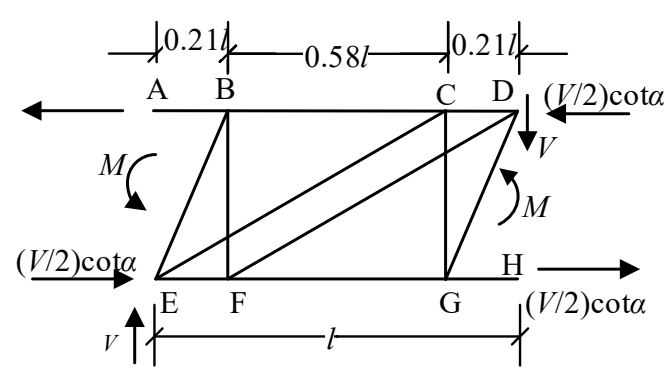

(b)

The mechanical behavior [40-47] is complicated when considering the floor slab effect; hence, the influence of slab is seldom considered by scholars. Therefore, the effect of floor slab is ignored in this study. In Fig. 4(b), the strut angle is calculated by using Eq. (11).

$\tan \theta_{1}=2 d / l$

\section{Result analysis and discussion}

\subsection{Theoretical equation}

The vertical deformation in the midspan of the coupling beam can be calculated as on the basis of the theoretical model in Fig. 4(b):

$$
\Delta=\sum \frac{F f L}{E A}
$$

where $\mathrm{AB}$ is the longitudinal chord, $\mathrm{BC}$ is the concrete compression strut, and $\mathrm{BD}$ is the vertical chord; their deformations are shown in Table 1.

The vertical deformation at the beam end when it yields is as follows:

$$
\Delta_{\mathrm{y}, \text { end }}=\frac{2 d V_{\mathrm{y}} \cot ^{3} \theta_{1}}{\rho_{\mathrm{s}} E_{\mathrm{s}} b d}+\frac{2 V_{\mathrm{y}} \csc ^{3} \theta_{1} \sec \theta_{1}}{b E_{\mathrm{c}}}+\frac{4 d V_{\mathrm{y}}}{\rho_{\mathrm{v}} E_{\mathrm{v}} b l}
$$

On the basis of Eqs. (2), (11), and (13), the effective stiffness of the coupling beam can be expressed as follows:

$$
K_{\mathrm{e}}=\frac{b \rho_{\mathrm{v}} E_{\mathrm{c}} \cot \theta_{1}}{\frac{2 E_{\mathrm{c}} \rho_{\mathrm{v}}}{E_{\mathrm{s}} \rho_{\mathrm{s}}} \cot ^{4} \theta_{1}+2 \rho_{\mathrm{v}} \csc ^{4} \theta_{1}+\frac{2 E_{\mathrm{c}}}{E_{\mathrm{v}}}}
$$


Let $n_{\mathrm{vc}}=E_{\mathrm{v}} / E_{\mathrm{c}}, \xi=\rho_{\mathrm{v}} / \rho_{\mathrm{s}}$, and $n_{\mathrm{vs}}=E_{\mathrm{v}} / E_{\mathrm{s}}$, and Eq. (14) can be transformed into Eq. (15):

$$
K_{\mathrm{e}}=\frac{n_{\mathrm{vc}} b \rho_{\mathrm{v}} E_{\mathrm{c}} \cot \theta_{1}}{2 \xi n_{\mathrm{vs}} \cot ^{4} \theta_{1}+2 n_{\mathrm{vc}} \rho_{\mathrm{v}} \csc ^{4} \theta_{1}+2}
$$

Table 1. Vertical deformation of each member

\begin{tabular}{l|l|l|l|l|l}
\hline Member & $\boldsymbol{F}$ & $\boldsymbol{f}$ & $\boldsymbol{L}$ & $\boldsymbol{E A}$ & Deformation \\
\hline $\mathrm{AB}$ & $V \cot \theta_{1}$ & $\cot \theta_{1}$ & $d \cot \theta_{1}$ & $E_{\mathrm{s}} A_{\mathrm{s}}$ & $V d \cot ^{3} \theta_{1} /\left(E_{\mathrm{s}} A_{\mathrm{s}}\right)$ \\
\hline $\mathrm{BC}$ & $-V / \sin \theta_{1}$ & $-1 / \sin \theta_{1}$ & $d / \sin \theta_{1}$ & $E_{\mathrm{c}} b d \cot \theta_{1}$ & $V \csc ^{3} \theta_{1} \sec \theta_{1} /\left(b E_{\mathrm{c}}\right)$ \\
\hline $\mathrm{BD}$ & $V$ & 1 & $d$ & $E_{\mathrm{v}} A_{\mathrm{v}}$ & $V d / E_{\mathrm{v}} A_{\mathrm{v}}$ \\
\hline
\end{tabular}

Note: $E_{\mathrm{s}}, E_{\mathrm{c}}$, and $E_{\mathrm{v}}$ are the elastic modulus of longitudinal reinforcement, concrete, and shear member, respectively; $A_{\mathrm{s}}$ and $A_{\mathrm{v}}$ are the crosssectional areas of longitudinal reinforcement and shear member; $A_{\mathrm{s}}=b d \rho_{\mathrm{s}}$ and $A_{\mathrm{v}}=b l \rho_{\mathrm{v}} / 2$ represent the effective depth of the coupling beam; $b$ is the beam width, $\rho_{\mathrm{s}}$ is the longitudinal reinforcement ratio, and $\rho_{\mathrm{v}}$ is the shear member ratio.

We can obtain the calculation equation of the stiffness reduction coefficient of the coupling beam by combining Eqs. (1) and (15), as shown in Eq. (16):

$$
\kappa=\frac{4 n_{\mathrm{vc}} \rho_{\mathrm{v}} \frac{l^{4}}{d h^{3}}}{\xi n_{\mathrm{vs}} \frac{l^{4}}{d^{4}}+n_{\mathrm{vc}} \rho_{\mathrm{v}}\left(\frac{l^{2}}{d^{2}}+4\right)^{2}+16}
$$

The modulus of elasticity of concrete adopted by reference [36] is:

$$
E_{\mathrm{c}}=\frac{10^{5}}{2.2+34.7 / f_{\mathrm{cu}, \mathrm{k}}}
$$

In SPRC, the steel plate participates in not only shear resistance but also compression resistance, increasing the stiffness of the coupling beam. Thus, the modulus of elasticity of concrete should be substituted with Eq. (18)

$$
E_{\mathrm{cn}}=\rho_{\mathrm{p}} E_{\mathrm{p}}+\left(1-\rho_{\mathrm{p}}\right) E_{\mathrm{c}}
$$

where $\rho_{\mathrm{p}}$ is the steel plate ratio, and $E_{\mathrm{p}}=2.0 \times 10^{5} \mathrm{MPa}$. The following expression is obtained by combining with Eq. (18):

$n_{\mathrm{vc}}=\frac{4.4 f_{\mathrm{cu}, \mathrm{k}}+69.4}{3.4 \rho_{\mathrm{p}} f_{\mathrm{cu}, \mathrm{k}}+69.4 \rho_{\mathrm{p}}+f_{\mathrm{cu}, \mathrm{k}}}$

The effective depth $d$, which denotes the distance from the compression edge to the centroid of the longitudinal reinforcements, is adopted in the stress analysis of CCBs and DCBs. In SPRCs, $d$ should be substituted with $d_{\mathrm{s}}$ :

$$
d_{\mathrm{s}}=d-\eta d / 3
$$

where $\eta$ can be calculated according to Reference [46], as shown in Eq. (21):

$$
\eta=\sqrt{\left[n_{\mathrm{sc}} \rho_{\mathrm{s}}+\left(n_{\mathrm{sc}}-1\right) \rho_{\mathrm{s}}^{\prime}+\left(n_{\mathrm{pc}}-1\right) \rho_{\mathrm{p}}\right]^{2}+2\left[n_{\mathrm{sc}} \rho_{\mathrm{s}}+\left(n_{\mathrm{sc}}-1\right) \rho_{\mathrm{s}}^{\prime} \frac{d^{\prime}}{d}+\left(n_{\mathrm{pc}}-1\right) \rho_{\mathrm{p}}\left(\frac{d_{1}^{\prime}}{d}+\frac{d_{\mathrm{w}}}{2 d}\right)\right]}-\left[n_{\mathrm{sc}} \rho_{\mathrm{s}}+\left(n_{\mathrm{sc}}-1\right) \rho_{\mathrm{s}}^{\prime}+\left(n_{\mathrm{pc}}-1\right) \rho_{\mathrm{p}}\right]
$$

where $\rho_{\mathrm{s}}^{\prime}$ is the ratio of the compression reinforcement, $n_{\mathrm{sc}}=E_{\mathrm{s}} / E_{\mathrm{c}}, n_{\mathrm{pc}}=E_{\mathrm{p}} / E_{\mathrm{c}}, d^{\prime}$ is the distance between the extreme compression edge to the centroid of the compression reinforcement, $d_{1}^{\prime}$ is the distance between the compression edge to the steel plate edge, and $d_{\mathrm{w}}$ is the steel plate depth.

Stirrups participate little in shear resistance [2, 46]. Hence, the effect of stirrups is ignored in this study, $\rho_{\mathrm{v}}=\rho_{\mathrm{p}}$, $\xi=\rho_{\mathrm{p}} / \rho_{\mathrm{s}}$, and the calculation equation of stiffness reduction coefficient of SPRC is as follows:

$$
\kappa_{\mathrm{SPRC}}=\frac{4 n \rho_{\mathrm{p}} \rho_{\mathrm{s}} \frac{l^{4}}{d_{\mathrm{s}} h^{3}}}{\frac{\rho_{\mathrm{p}} l^{4}}{d_{\mathrm{s}}^{4}}+n \rho_{\mathrm{p}} \rho_{\mathrm{s}}\left(\frac{l^{2}}{d_{\mathrm{s}}^{2}}+4\right)^{2}+16 \rho_{\mathrm{s}}}
$$

where $d_{\mathrm{s}}$ is calculated by using Eq. (20), and $n_{\mathrm{vc}}$ is determined by utilizing Eq. (19).

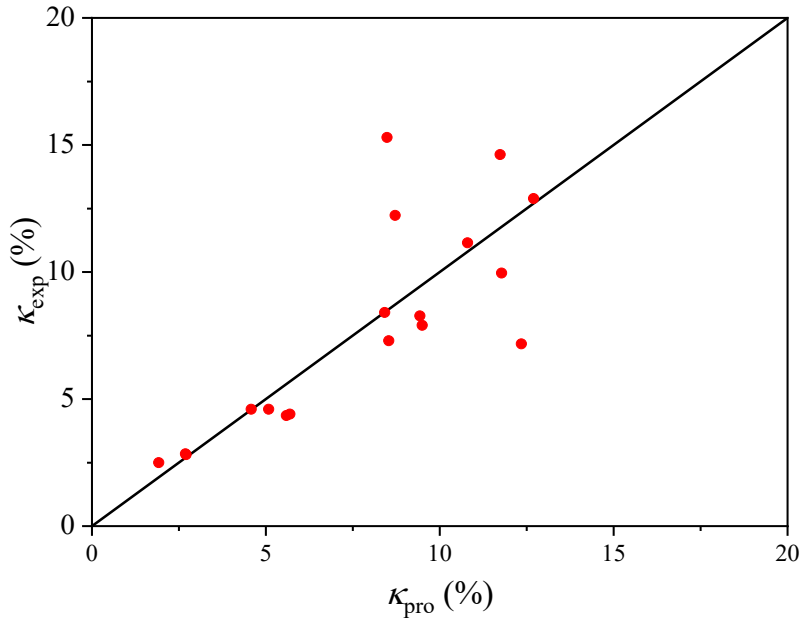

Fig. 5. Comparison between experimental results and prediction results

\subsection{Equation verification}

Table 2 and Fig. 5 show the comparison between the predicted stiffness reduction coefficients and the test values of 18 SPRCs. $\kappa_{\exp }$ represents the experimental value, and 
$\kappa_{\text {pro }}$ denotes the stiffness reduction coefficient calculated by using Eq. (22).

Table. 2. Experimental verification of the proposed formula for SPRCs

\begin{tabular}{|c|c|c|c|c|c|c|c|c|c|c|}
\hline Ref & Specimen & $f_{\mathrm{cu}} / \mathbf{M P a}$ & $\rho_{\mathrm{s}} / \%$ & $\rho_{\mathrm{p}} / \%$ & $l / h$ & $l / d_{\mathrm{s}}$ & $d_{\mathrm{w}} / \mathbf{m m}$ & $\kappa_{\exp } / \%$ & $\kappa_{\mathrm{pro}} / \%$ & $\kappa_{\exp } / \kappa_{\text {pro }}$ \\
\hline$[1]$ & Unit3 & 51.9 & 1.29 & 4.4 & 2.5 & 3.16 & 240 & 11.78 & 10.04 & 1.135 \\
\hline [48] & Specimen 1 & 55.6 & 2.05 & 5.95 & 2.5 & 3.23 & 250 & 12.70 & 13.77 & 0.922 \\
\hline \multirow{6}{*}{ [49] } & CB15-1 & 51 & 0.57 & 1.87 & 1.5 & 1.76 & 220 & 5.69 & 4.50 & 1.265 \\
\hline & CB15-2 & 52 & 0.57 & 1.79 & 1.5 & 1.75 & 420 & 5.59 & 4.44 & 1.259 \\
\hline & CB15-3 & 54.3 & 0.57 & 2.98 & 1.5 & 1.76 & 350 & 4.58 & 4.77 & 0.960 \\
\hline & CB15-4 & 53 & 0.57 & 2.84 & 1.5 & 1.76 & 200 & 5.08 & 4.77 & 1.065 \\
\hline & CB25-1 & 42.3 & 1.98 & 1.63 & 2.5 & 3.12 & 220 & 8.49 & 15.91 & 0.533 \\
\hline & CB25-2 & 49.3 & 1.98 & 3.26 & 2.5 & 3.12 & 220 & 11.74 & 15.68 & 0.748 \\
\hline \multirow{2}{*}[50]{} & SPrc-Bs2 & 47.8 & 0.47 & 2.25 & 1.17 & 1.34 & 540 & 2.69 & 2.88 & 0.934 \\
\hline & SPrc-Bg & 51.2 & 0.47 & 2.25 & 1.17 & 1.34 & 540 & 2.71 & 2.84 & 0.954 \\
\hline \multirow{5}{*}[15]{} & PRC-CB1 & 58.16 & 1.65 & 3.07 & 1.5 & 1.87 & 290 & 9.50 & 8.03 & 1.183 \\
\hline & PRC-CB2 & 58.16 & 1.65 & 4.09 & 1.5 & 1.87 & 290 & 9.43 & 8.49 & 1.110 \\
\hline & PRC-CB3 & 58.16 & 1.65 & 5.11 & 1.5 & 1.87 & 290 & 8.42 & 8.72 & 0.965 \\
\hline & PRC-CB6 & 58.16 & 1.65 & 4.09 & 0.9 & 1.12 & 290 & 1.92 & 2.50 & 0.769 \\
\hline & PRC-CB7 & 58.16 & 1.65 & 4.09 & 2 & 2.50 & 290 & 10.80 & 11.61 & 0.930 \\
\hline \multirow{3}{*}{ [3] } & SPC-1 & 50.8 & 0.88 & 4.38 & 2.5 & 3.08 & 350 & 8.54 & 8.00 & 1.067 \\
\hline & SPC-2 & 50.8 & 1.56 & 4.38 & 2.5 & 3.09 & 350 & 8.72 & 13.02 & 0.669 \\
\hline & $\mathrm{SPC}-3$ & 56.1 & 0.88 & 4.38 & 2.5 & 3.08 & 350 & 12.35 & 7.87 & 1.569 \\
\hline \multicolumn{2}{|c|}{ Mean } & & & & & & & & & 1.002 \\
\hline \multicolumn{2}{|c|}{ Coefficient of variation } & & & & & & & & & 0.242 \\
\hline
\end{tabular}

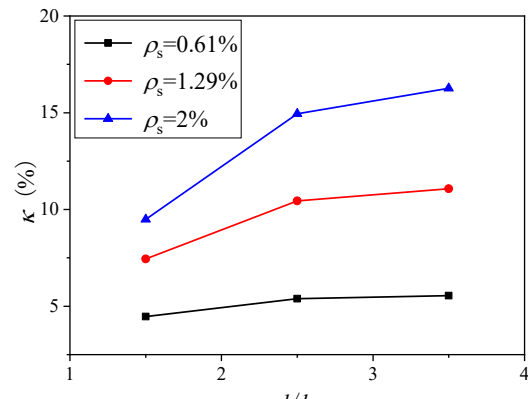

(a) $f_{\mathrm{cu}}=50 \mathrm{MPa}, \rho_{\mathrm{p}}=4.4 \%$

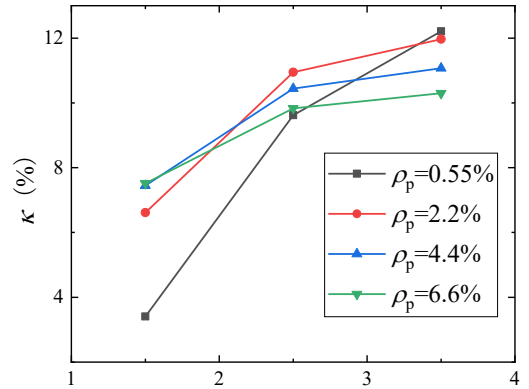

$l / h$

(b) $f_{\text {cu }}=50 \mathrm{MPa}, \rho_{\mathrm{s}}=1.29 \%$

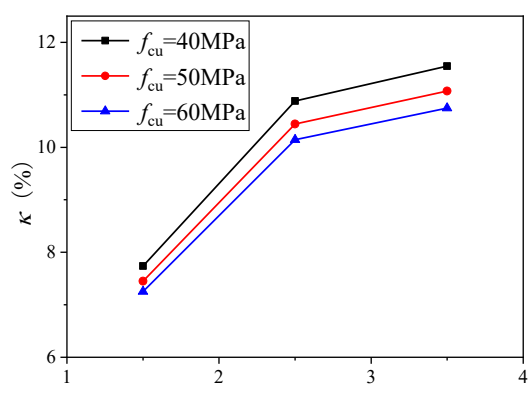

(c) $\rho_{\mathrm{p}}=4.4 \%, \rho_{\mathrm{s}}=1.29 \%$

Fig. 7. Influence of the various parameters on the stiffness reduction coefficients of SPRCs

\subsection{Parameter analysis}

The comparison of Table 2 and Fig. 5 show that the theoretical equation in this study is in good agreement with the experimental results, and parameter analysis can be performed. Specimen Unit 3 with a span-depth ratio of 2.5, tested by Lam et al. [1], is considered the reference specimen in the parametric study for SPRCs. Table 3 illustrates the parameter variations, and Fig. 6 shows the details of specimen Unit 3, which has a concrete cube compressive strength $f_{\mathrm{cu}}$ of $51.9 \mathrm{MPa}$. The analytical results are shown in Fig. 7.

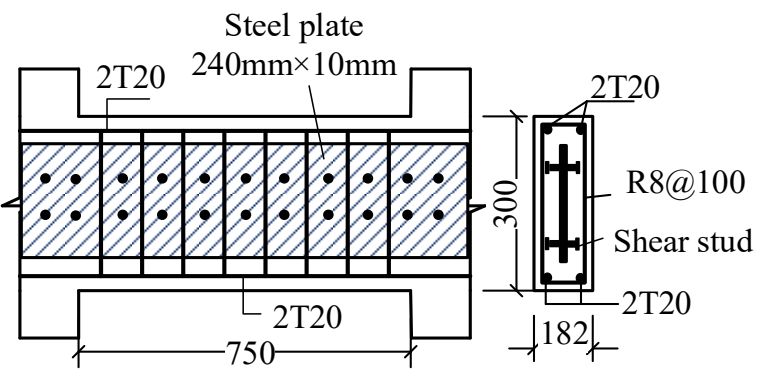

Fig. 6. Details of Unit 3 (in $\mathrm{mm}$ )
Table 3. Parameter variations of SPRCs

\begin{tabular}{l|l|l|l|l}
\hline \multicolumn{1}{c|}{ Parameters } & \multicolumn{4}{|c}{ Various factors } \\
\hline$l / h$ & 1.5 & 2.5 & 3.5 & \\
$\rho_{\mathrm{p}} / \%$ & 0.55 & 2.2 & 4.4 & 6.6 \\
$\rho_{\mathrm{s}}\left(\rho_{\mathrm{s}}^{\prime}\right) / \%$ & 0.61 & 1.29 & 2.0 & \\
$f_{\mathrm{cu}} / \mathrm{MPa}$ & 40 & 50 & 60 & \\
\hline
\end{tabular}

Note: $\rho_{\mathrm{s}}=\rho_{\mathrm{s}}^{\prime}$

Fig. 7 shows that the stiffness reduction coefficient $\kappa$ increases along the span-depth ratio and longitudinal reinforcement ratio. The two impacting factors show a correlation. Variable $\kappa$ significantly increases with the longitudinal reinforcement ratio if the beam span-depth ratio is large. Meanwhile, $\kappa$ decreases with the increase in the concrete compressive strength. If the coupling beam has a small span-depth ratio, then the increase in the steel plate ratio is an effective way to enhance the stiffness reduction coefficient, while if the span-depth ratio is more than 2.5 , increasing the steel plate ratio will result in a decrease in the stiffness reduction coefficient. This phenomenon can be verified by Shi's test results [15], in which specimens PRC$\mathrm{CB} 1, \mathrm{PRC}-\mathrm{CB} 2$ and PRC-CB3 have the steel plate ratios of $3.07 \%, 4.09 \%$, and $5.11 \%$ respectively (the other parameters are identical), meanwhile, the stiffness reduction coefficients decreased from $9.5 \%$ to $9.43 \%$ and $8.42 \%$. 


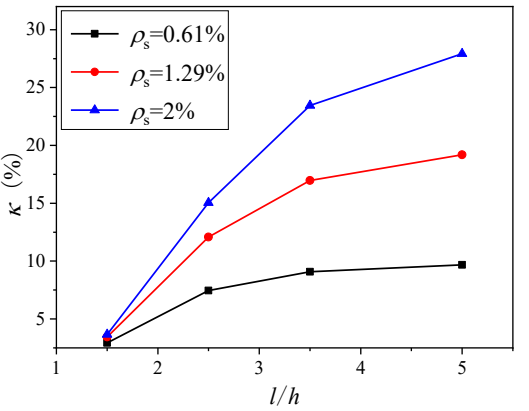

(a) $f_{\mathrm{cu}}=50 \mathrm{MPa}, \rho_{\mathrm{sv}}=0.55 \%$

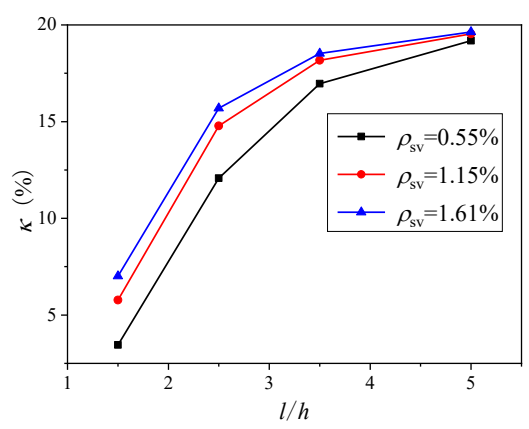

(b) $f_{\mathrm{cu}}=50 \mathrm{MPa}, \rho_{\mathrm{s}}=1.29 \%$

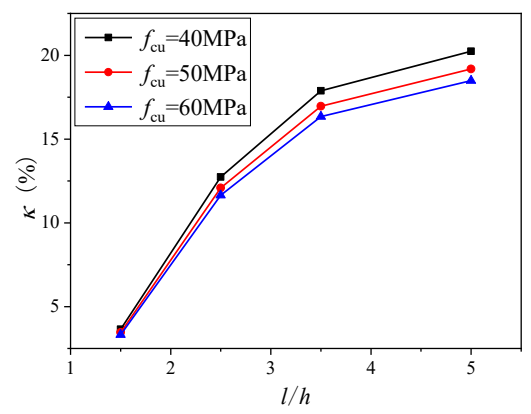

(c) $\rho_{\mathrm{sv}}=0.55 \%, \rho_{\mathrm{s}}=1.29 \%$

Fig. 8. Influence of the various parameters on the stiffness reduction coefficients of CCBs [36]

Fig. 8 shows the parametric analysis results on $\mathrm{CCBs}$ from reference [36], which shows a similar change law with the stiffness reduction coefficient of SPRCs (Fig. 7), other than the effect of the shear member content. The stiffness reduction coefficient of CCBs increases with the shear member content (stirrup ratio). In SPRCs, the increase in the shear member content (steel plate) will result in the decrease in the stiffness reduction coefficient, provided that SPRC has a large span-depth ratio. The difference can be explained as follows: the stirrups only participate in shear resistance, while the steel plates participate in not only in shear resistance but also compression resistance. The increase in the steel plate ratio can enhance the initial stiffness and effective stiffness. If SPRC is with a large span-depth ratio, then the initial stiffness of the coupling beam quickly increases, causing the decrease in the stiffness reduction coefficient.

\section{Conclusions}

On the basis of STM, this study proposed a calculation equation for predicting the stiffness reduction coefficient of SPRCs to investigate the stiffness characters of SPRCs and show the interaction mechanism between the various influencing factors and the stiffness reduction coefficient of SPRC. Parameter analysis was then carried out. The comparison with the existing study on the stiffness reduction coefficient of CCBs was also implemented. The following conclusions could be drawn:

(1) The theoretical equation proposed in this study, Eq. (22), can comprehensively reflect the influence of concrete compressive strength, longitudinal reinforcement ratio, span-depth ratio, steel pate ratio, and steel plate depth. The accuracy of the proposed equation is high, and the discreteness is small, hence, it can provide a good estimation to the stiffness reduction coefficient of SPRCs.

(2) The stiffness reduction coefficient of SPRCs $(\kappa)$ increases with the span-depth ratio and longitudinal reinforcement ratio. The two influencing factors show a correlation. $\kappa$ significantly increases with the longitudinal reinforcement ratio if the beam span-depth ratio is large; otherwise, if the beam span-depth ratio is small, the increase of steel plate ratio is an effective way to enhance the stiffness reduction coefficient. If the span-depth ratio is more than 2.5 , increasing the steel plate ratio will result in a decrease in the stiffness reduction coefficient; $\kappa$ decreases with the increase in the concrete compressive strength, but the effect is less.

(3) The change law of the stiffness reduction coefficient of SPRCs is similar with that of CCBs, other than the effect of the shear member content. The stiffness reduction coefficient of CCBs increases with the shear member content (stirrup ratio), while that of SPRCs decreases with the increase in the shear member content (steel plate), provided that SPRC has a large span-depth ratio.

Based on the STM, a theoretical equation is proposed to effectively predict the stiffness reduction coefficient of SPRCs in this study. The equation benefits from high precision, systematic consideration, and other features and can be used as a guide for the seismic design of shear/core walls. However, the slab effect was not considered in this study due to the complexity effect of the floor slab and the lack of test data. Accordingly, the proposed equation has flaws and cannot perfectly reflect the actual situation. This research team will conduct experimental and FEA analysis to further study the floor slab effect on the stiffness reduction coefficient of SPRCs. The equation in this study. will also be revised for better guiding the structural design.

\section{Acknowledgements}

This work was financially supported by the National Natural Science Foundation of China (No. 51578235), Hunan Natural Science Foundation (2020JJ5018 and 2020JJ5020), and the Scientific Research Project of Education Department of Hunan Province (19A095,19B099, 20B108, and 20C0363).

This is an Open Access article distributed under the terms of the Creative Commons Attribution License.

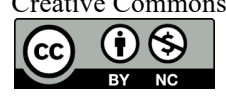

\section{Reference}

1. Lam, Y. W., Leung, R., Pam, H., "Experimental study on embedded steel plate composite coupling beams". ASCE Journal of Structural Engineering, 131(8), 2005, pp. 1294-1302.

2. Tian, J. B., Shi, Q. X., Tao, Y., Liu Y. H., "Research on mechanics and deformation performance of plate-reinforced composite coupling beams with small span-to-depth ratio". Journal of Building Structures, 37(12), 2016, pp. 83-96. (in Chinese)
3. Hou, W., Chen, B., Guo, Z. X., Zhang, J., "Experimental study on seismic behavior of embedded steel plate reinforced concrete coupling beams". China Civil Engineering Journal, 50(2), 2017, pp.9-18. (in Chinese)

4. NZS 3101. "Concrete structures standard". Wellington: The Trading Arm of the Standards Council, New Zealand, 1995, pp.293-293.

5. ACI 318-14. "Building code requirements for structural concrete". Farmington Hills: American Concrete Institute, USA, 2014, pp.72-72. 
6. GB50011-2010 "Code for seismic design of building”. Beijing: Ministry of Housing and Urban-Rural Development of the People's Republic of China, China, 2016, pp. 377-377. (in Chinese)

7. Xiao, C. Z., Deng, F., "Study on deformation of flexural stiffness reduction factor of coupling beams in frame-core structures". Journal of Building Structures, 39(10), 2018, pp.164-173. (in Chinese)

8. Chen, C. H., Wang, C. K., Zhang, H., "Edification of shaking table test on structure design of high-rise buildings". Journal of Building Structures, 41(7), 2020, pp.1-14.(in Chinese)

9. Paulay, T., Priestley, M. J. N., "Seismic design of reinforced concrete and masonry buildings". New York: Wiley, USA, 1992, pp.99-102.

10. Vu, N. S., Li, B., Beye, K., "Effective stiffness of reinforced concrete coupling beams". Engineering Structures, 76(October), 2014, pp. 371-382.

11. Paulay, T., Binney, J. R., "Diagonally reinforced coupling beams of shear walls". ACI Special Publication, 42(SP), 1974, pp. 579-598.

12. Tegos, I. A., Penelis, G. G., "Seismic resistance of short columns and coupling beams reinforced with inclined bars". ACI Structural Journal, 85(1), 1998, pp. 82-88.

13. Shahrooz, B. M., Remmetter, M. E., Qin, F., "Seismic design and performance of composite coupled walls". ASCE Journal of Structural Engineering, 119 (11), 1993, pp. 3291-3309.

14. Subedi, N., Baglin, P., "Ultimate load analysis of steel plate reinforced concrete beams". Engineering Structures, 23(9), 2001, pp. 1068-1079.

15. Shi, Q. X., Tian, J. B., Wang, Q. W., "Experimental research on seismic behavior of plate-reinforced composite coupling beams with small span-to-depth ratio". Journal of Building Structures, 36(2), 2015, pp. 104-114 (in Chinese)

16. Hu, H. S., Nie, J. G., Wang, Y. H., "Shear capacity of concrete-filled steel plate composite coupling beams". Journal of Constructional Steel Research, 118(MAR.), 2016, pp.76-90.

17. Muhammad, N. S. H., Mazin, M. S., Lip, H. T., "Behavior of concrete beams reinforced with steel plates". ACI Structural Journal, 115(5), 2018, pp. 1307-1315.

18. Wang, M. F., Luo, D., Hu, Z. Q., "Seismic performance of steelenhanced damping concrete core walls with concealed steel plate bracings". Engineering Structures, 213(June), 2020, pp. 1-23.

19. Wang, M. F., Hu, Z. Q., Luo, D., "Quasi-static cyclic test on high damping concrete core wall with steel plate concealed bracings under diagonal loading". Earthquake Engineering and Engineering Vibration, 39(2), 2019, pp. 18-26. (in Chinese)

20. Hu, Z. Q., Wang, M. F., Luo, D., Lv, W. R., "Study on seismic performance levels and deformation limits of core tubes". Word Earthquake Engineering, 36(2), 2020, pp. 92-100. (in Chinese)

21. Huang, Y., Hu, X. F., Wan, X. W., Hong, L. L., "Effective stiffness of reinforced concrete shear wall under lateral load". Journal of Hunan University (Natural Sciences), 46(7), 2019, pp.11-18. (in Chinese)

22. Sharifi, M., Shafieian, M., "Effective stiffness of concrete shear walls based on statistical analysis". Structural Concrete, 19(6), 2018, pp. $1560-1576$

23. Hou, X. W., Wang, Y., Yang, Z. Y., "Application of method on stiffness reduction coefficient of coupling beam". Building Structure, 48(9), 2018, pp. 28-33. (in Chinese)

24. Kim, J. H., Mander, J. B., "Influence of transverse reinforcement on elastic shear stiffness of cracked concrete elements". Engineering Structures, 29(8), 2007, pp. 1798-807.

25. Bernardo, L. F. A., Teixeirab, M. M., "Modified softened truss-model for prestressed concrete beams under torsion". Journal of Building Engineering, 19(September), 2018, pp. 49-61.

26. Bernardo, L. F. A., Teixeirab, M. M., "Refined softened-truss model with efficient solution procedure for reinforced concrete members under torsion combined with bending”. Structures, 26(May), 2020, pp 651-669.

27. Bernardo, L. F. A., Taborda, C. S. B., "Softened truss model for reinforced concrete beams under torsion combined with axial force". Applied Mechanics, 1(1), 2020, pp. 79-96.

28. Dhahir, M. K., "Strut and tie modeling of deep beams shear strengthened with FRP laminates". Composite Structures, 193(Jun), 2018, pp. 247-259.

29. Nabilah, A. B., Koh, C. G., Safiee, N. A., "Analysis of conventionally reinforced coupling beams using non-linear strut and tie model". Proceedings of the ICE-Structures, 173(6), 2019, pp. 1-32.
30. Luís, F. A. B., Jorge, M. A. A., "A unified softened truss model for RC and PC beams under torsion". Journal of Building Engineering, 32(November), 2020, 101467.

31. Xia, Y., Langelaar, M., Hendriks, M., "Automated optimization-based generation and quantitative evaluation of strut-and-tie models". Computers and Structures, 238(October), 2020, 106297.

32. Xia, Y., Langelaar, M., Hendriks, M., "A critical evaluation of topology optimization results for strut-and-tie modeling of reinforced concrete". Computer-Aided Civil and Infrastructure Engineering, 35(8), 2020, pp. 850-869.

33. Meléndez, C., Sagaseta, J., Sosa, P. F. M., Rubio, L. P., "Refined three-dimensional strut-and-tie model for analysis and design of fourpile caps". ACI Structural Journal, 116(4), 2019, pp. 15-29.

34. Yun, Y. M., Chae, H. S., Kim, B., Ramirez, J. A., "Verification of three-dimensional grid strut-and-tie model approach in structural concrete". ACI Structural Journal, 115(1), 2018, pp.27-40.

35. Zhou, L. Y., Liu, Z., He, Z. Q., "Elastic-to-plastic strut-and-tie model for deep beams". Structural Concrete, 23(4), 2018, pp. 1049-1062.

36. Hu, Z. Q., Lv, W. R., Wu, Y. S., Zhang, M., "Analysis of stiffness reduction coefficient of conventionally reinforced concrete coupling beams on the bias of strut-and-tie model". Journal of Engineering Science and Technology Review, 13(5), 2020, pp. 82-89.

37. Oviedo, R., Gutierrez, S., Santa, M. H., "Experimental evaluation of optimized strut-and-tie models for a dapped beam". Structural concrete, 17(3), 2016, pp. 469-480.

38. Wei, W., Shao, C. J., Xiao, Z. H., "Experimental study on effective stiffness of reinforced concrete hollow piers". China Civil Engineering Journal, 52(10), 2019, pp. 101-110. (in Chinese)

39. Lin, L. P., Liu, K. D., He, J. Q., "Numerical method for consolidation factor on reserve bend point". Journal of Railway Science and Engineering, 17(3), 2020, pp. 623-627. (in Chinese)

40. Kotsovou, G. M., Cotsovos, D. M., "Shear failure criterion for RC Tbeams". Engineering Structures, 160(April), 2018, pp. 44-55.

41. Men, J. J., Xiong, L. Q., Lei, M. K., "Seismic performance of reinforced concrete column-steel beam subassemblies considering effect of RC slab". Journal of Building Structures, 40(12), 2019, pp.69-87. (in Chinese)

42. Du, K., Teng, N., Yan, D., "Experimental study on the effect of floor slab on the progressive collapse resistance of RC spatial frame structure". China Civil Engineering Journal, 52(6), 2019, pp. 14-23. (in Chinese)

43. Tian, J. B., Wang, C. Y., Shi, Q. X., Ren, W. G., "Seismic behavior control method for hybrid coupled shear wall system with platereinforced composite coupling beam". China Civil Engineering Journal, 40(S1), 2019, pp. 1-10. (in Chinese)

44. Lv, B. B., Tan, C. M., Liu, X., "Probabilistic model analysis for shear capacity of plate-reinforced composite coupling beams". Structural Engineers, 36(6), 2020, pp. 44-52. (in Chinese)

45. Tian, J. B., Shi, Q. X., Liu, Y. H., Li, S., "Research on aseismic performance of PRC coupling beam- hybird coupled shear wall system". Engineering Mechanics, 35(11), 2018, pp. 53-67. (in Chinese)

46. Tian, J. B., Shi, Q. X., Wang, N., Wang, P., "Shear strength of platereinforced composite coupling beams with small span-to-depth ratio using softened strut-and-tie model". Engineering Mechanics, 33(5), 2016, pp. 142-149. (in Chinese)

47. Zhang, J., Wu, Y. T., Yang, Y. B., Wang, B., "Performance-based design method and pushover analysis on steel plate and concrete composite coupled shear walls". Progress in Steel Building Structures, 23(03), 2021, pp. 12-22. (in Chinese)

48. Lam, W. Y., Su, R. K. L., Pam, H. J., "Strength and ductility of embedded steel composite coupling beams". Advances in Structural Engineering, 6(1), 2003, pp.23-35.

49. Zhang, G., "Experimental study on seismic behavior of steel plate reinforced concrete coupling beams". Master thesis of Tsinghua University, China, 2005, pp. 28-78. (in Chinese)

50. Su, R. K. L., Lam, W. Y., Pam, H. J., "Experimental study of platereinforced composite deep coupling beams". The structural design of tall and special buildings, 18(3), 2009, pp. 235-257. 